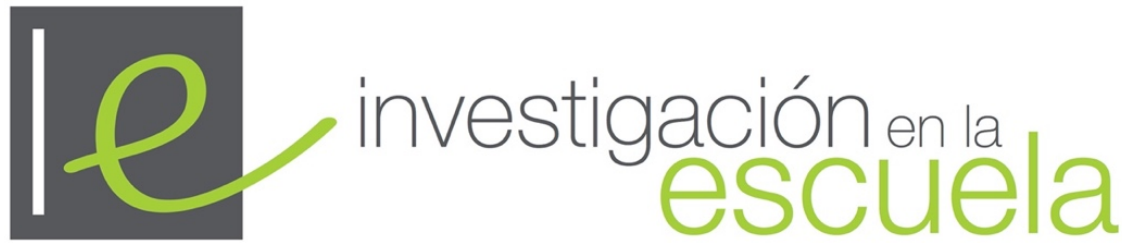

Revista de Investigación e Innovación Educativa nº 101, 2020 | e-ISSN 2443-9991

\title{
El patrimonio como recurso para el desarrollo formativo de alumnos y profesores. Experiencia didáctica: "Farmington Junior High y su entorno patrimonial"
}

Heritage as a resource for the educational development of students and teachers. Learning experience: "Farmington Junior High and its heritage setting"

iD Dr. Carlos Teófilo López Arroyo es Profesor Asociado en la Facultad de Educación, Psicología y Ciencias del Deporte de la Universidad de Huelva (España)·carlos.lopez@ddi.uhu.es https://orcid.org/0000-0001-5688-9134

Resumen. "Farmington Junior High y su entorno patrimonial” fue una investigación basada en la experiencia didáctica llevada a cabo con un grupo de estudiantes en una escuela de Secundaria de Utah en los Estados Unidos. El presente trabajo muestra de forma práctica las enormes posibilidades que ofrece la Educación Patrimonial como camino de indagación e innovación en las aulas. Para ello, empleando una metodología cualitativa de carácter mixto, se contrastaron tablas de categorías, de observación, entrevistas y encuestas tanto al inicio como al final del estudio. Las concepciones expresadas por el alumnado de Farmington sobre su patrimonio cercano y la evolución lograda, configuraron un estudio de casos aplicable en muchos aspectos a otros contextos educativos. Los resultados demuestran que se alcanzó un modelo de enseñanza y comunicación deseable, situando el patrimonio en el foco del interés comunitario. La didáctica patrimonial llegó a constituirse en una excelente herramienta para el desarrollo profesional docente. Se apuesta por una necesaria actualización y adecuación escolar del concepto de patrimonio, en consonancia a las necesidades sociales de hoy, a partir de la detección de bienes de interés próximo y el desarrollo de dinámicas de investigación que resulten motivadoras.

Abstract. "Farmington Junior High and its heritage setting" was research based on the didactic experience carried out with a group of students at a Utah secondary school in the United States. The current study shows in practical terms the enormous possibilities that Heritage Education offers as a path of investigation and innovation in the classroom. For this, category and observation tables, interviews and surveys were corroborated employing a mixed qualitative methodology both at the beginning and the end of the study. The concepts expressed by the students at Farmington about their surrounding heritage, and the evolution accomplished, shaped a case study applicable in many aspects to other educational contexts. The results show that a desirable model of teaching and communication was achieved, placing heritage in the focus of community interest. Heritage didactics became an excellent tool for professional teaching development. There is a commitment to a necessary update and a curriculum adaptation of the concept of heritage, in line with current social needs, based on the detection of assets of close interest and the development of research dynamics that are motivating.

\section{Palabras clave $\cdot$ Keywords}

Educación Patrimonial, experiencia didáctica, desarrollo profesional, didáctica Ciencias Sociales.

Heritage Education, learning experience, professional development, Social Science education, educational research and innovation. 


\section{Introducción}

¿Qué entienden nuestros estudiantes por patrimonio?, ¿conocen y valoran lo suficiente el que se encuentra próximo a su escuela?, ¿qué posibilidades didácticas y de investigación ofrece trabajar con dicha temática? Estas y otras preguntas relevantes recibirán respuestas mediante una investigación educativa basada en la práctica docente diaria. Se describe a partir de una visión holística e integradora del patrimonio, cómo la Educación Patrimonial puede convertirse de una forma real en un vehículo de investigación para alcanzar el éxito formativo. Para ello, nos trasladaremos a Farmington, una localidad perteneciente al Estado de Utah en los Estados Unidos, donde en su Junior High se desarrolla a través de una experiencia didáctica original, una estudio que no solo transformó las concepciones tradicionales sobre patrimonio de sus estudiantes, también certificará una apuesta relevante que se sitúa hoy de plena actualidad, nos referimos a las posibilidades que ofrece trabajar con el patrimonio como instrumento de educación ciudadana y potenciador de identidades ${ }^{1}$. Además, el diseño del estudio de casos concreto sobre concepciones patrimoniales permite ofrecer un claro ejemplo de una herramienta accesible y eficaz para generar una didáctica patrimonial innovadora vinculada al desarrollo profesional docente. Partiendo de la fundamentación metodológica del estudio se concreta el diseño de una investigación exportable a otros contextos escolares.

\section{Investigación e innovación patrimonial}

Es tarea de todos los agentes implicados intentar que la nueva didáctica del patrimonio supere la erudición y el aislamiento tradicional que le acompaña, para ello, existen cada vez más propuestas que plantean una comunicación patrimonial flexible, dinámica e interactiva, que sin duda, ayudan a comprender mejor el proceso de evolución de las sociedades y sus características definitorias (Martín y Cuenca, 2015). La metodología pasa ineludiblemente por salidas fuera de las aulas, por la experimentación personal con interacciones continuas, se hace así necesaria una contextualización espacial y original del patrimonio, vinculando dichos elementos a la sociedad que los genera. En ese sentido resulta clave promover una visión patrimonial integradora, compleja y crítica, fundamentada en metodologías de carácter investigativo que aspiran a su vez a la reconstrucción de significados concretos y que posibilitan la intervención en el medio sociocultural (Cuenca, 2014). Se pasa de la tradicional pasividad del alumno espectador al intervencionismo y compromiso crítico de ciudadanos sensibles con los problemas socioambientales relevantes de su entorno ${ }^{2}$. Esos cambios también deben ir acompañados de una actualización de los procesos respecto al uso de nuevas tecnologías; las generaciones de jóvenes definidas bajo el apelativo de nativos digitales sienten ya una identificación plena con ellas, por lo que su inclusión dentro de los planes educativos resulta imprescindible. En esa línea destacan varios estudios sobre los modelos de la arqueología virtual como fuente de materiales escolares, la reconstrucción digital de espacios y el uso didáctico de las nuevas tecnologías (Vicent, Rivero y Feliu, 2015), también los que promueven el uso de aplicaciones de realidad aumentada para la enseñanza - aprendizaje del patrimonio (Luna, Ibáñez y Rivero, 2019).

Para trabajar el patrimonio se opta por un modelo de investigación escolar que posibilita una estrategia directa de enseñanza y de desarrollo profesional (Lucas y Delgado-Algarra, 2020). Se parte de interrogantes asociados a temas de interés, de los que los estudiantes manifiestan sus conocimientos iniciales o previos. A continuación, deben ponerse de acuerdo en cuanto al diseño y el desarrollo de la investigación. Estos pasos resultan claves puesto que el alumnado se siente protagonista de su propio proceso de aprendizaje, hace que el conocimiento resulte significativo y se vincule de forma directa y permanente a la persona. De las respuestas obtenidas se generan nuevos interrogantes que hacen que la investigación cobre de nuevo un pleno sentido. En este modelo comunicar los resultados alcanzados resulta fundamental puesto que refuerza el trabajo personal o en equipo realizado, los estudiantes ya no solo se consideran protagonistas de su propio proceso de aprendizaje sino también transmisores de conocimientos a los demás. El trabajo por proyectos acercará a la realidad a través de la resolución de problemas, y no en torno a temas como suele suceder; dichos problemas se convierten en el punto de partida y ejes vertebradores de la dinámica (Pozuelos, 2007).

\footnotetext{
${ }^{1}$ Lo expuesto en el presente artículo es una síntesis de una investigación de mayor calado que tuvo como resultado la tesis doctoral con título: "El patrimonio en el contexto escolar. "Análisis de concepciones como vehículo para el desarrollo profesional docente. Experiencia didáctica: Farmington Junior High y su entorno patrimonial. Utah”. Universidad de Huelva. 2017.

2 El estudio pertenece al proyecto de investigación "Educación Patrimonial para la inteligencia territorial y emocional de la ciudadanía" (EPITEC). (MINECO/FEDER, con código de referencia EDU2015-67953-P). Y aborda varios aspectos significativos, todos ellos, sin duda, relacionados con las enormes posibilidades que posee la Educación Patrimonial dentro del contexto escolar.
} 
Urge así, una decidida apuesta por fomentar aprendizajes significativos, basados en valoraciones comprensivas y críticas sobre su entorno.

Estudios como el presente son escasos, esta experiencia didáctica nace de la necesidad de planteamientos escolares reales desde el propio aula (Fontal, 2007), (López-Arroyo, 2014 y 2017) y la contribución de estos en el desarrollo profesional demuestran que el éxito depende básicamente de tres factores: en primer lugar, señalar unas actividades con objetivos patrimoniales claros; en segundo lugar, del contexto socio-cultural donde se enmarque el programa; y por último, de la puesta en práctica de actividades complementarias en la propia localidad. En esa línea de innovación docente destacan algunos trabajos enmarcados en el programa "Vivir y Sentir el Patrimonio" de la Junta de Andalucía, en el que se favorece el estudio del patrimonio local o regional en sus múltiples tipologías y desde un enfoque multidisciplinar (Trabajo y López-Cruz, 2019). La propuesta que aquí se desarrolla facilitará los instrumentos necesarios para que los estudiantes construyan a través de su propia iniciativa una nueva visión holística de su patrimonio, acorde con los principios teórico-prácticos que defendemos, basados en: las posibilidades de la ciudad educadora (Prats y Santacana, 2009; Coma y Santacana, 2010), los valores cívicos de la educación para la ciudadanía (Lucas y Estepa, 2016; Cuenca, Martín, Estepa, 2020) y las ventajas metodológicas del aprender investigando (Cañal, Pozuelo y Travé, 2005; Aguirre, 2012).

\section{Metodología}

Teniendo presente que se trata de una investigación de ámbito educativo, ninguna metodología dará por sí sola respuestas a todas las preguntas, por lo que resulta conveniente hablar de un continuo metodológico y no de polaridades opuestas (Latorre, Del Rincón y Arnal, 2020). La opción metodológica de la presente investigación se define como descriptiva-interpretativa, ya que se basa en la observación y recogida de datos, con un enfoque cualitativo de carácter mixto, atendiendo a una evaluación de tipo continuo y formativo. La finalidad de la investigación es desarrollar un estudio de casos referido a las concepciones que sobre el patrimonio próximo tienen los estudiantes de Farmington, para que a través de él pueda implementarse la capacidad que tiene la didáctica del patrimonio como fundamento de progresión de mi propio desarrollo profesional como docente (Tabla 1). Para todo ese gran objetivo es importante comprender e interpretar la realidad del alumnado, los significados que como individuos conceden a sus acciones, percepciones e intenciones, interpretando todas las situaciones que hacen único al caso que nos ocupa.

Tabla 1

Sistema de categorias creado como instrumento marco para la presente investigación

\begin{tabular}{|c|c|c|c|}
\hline Categorías & Variables & Indicadores & Descriptores \\
\hline \multirow{11}{*}{$\begin{array}{l}\text { Categoría I: } \\
\text { Concepto de } \\
\text { patrimonio }\end{array}$} & \multirow{7}{*}{$\begin{array}{l}\text { 1. Perspectiva } \\
\text { sobre el patrimonio }\end{array}$} & Excepcionalista & $\begin{array}{l}\text { Escasez, rareza, singularidad y valor } \\
\text { crematístico. }\end{array}$ \\
\hline & & Monumentalista & $\begin{array}{ccc}\text { Grandiosidad } & \text { (espectacularidad y grandes } \\
\text { dimensiones). } & \text { Reconocido prestigio de }\end{array}$ \\
\hline & & & $\begin{array}{l}\text { elementos naturales, histórico-artísticos, } \\
\text { etnológicos y científico tecnológicos. }\end{array}$ \\
\hline & & Estética & Belleza natural, artística y estilística. \\
\hline & & Histórica & Antigüedad. \\
\hline & & Simbólico-identitaria & $\begin{array}{l}\text { Elementos simbólicos que caracterizan a una } \\
\text { sociedad. }\end{array}$ \\
\hline & & Social-ciudadana & Relevancia para la comunidad. \\
\hline & \multirow{4}{*}{$\begin{array}{l}\text { 2. Tipos de } \\
\text { patrimonio }\end{array}$} & $\begin{array}{l}\text { Natural-Histórico- } \\
\text { Artístico }\end{array}$ & $\begin{array}{lcc}\text { Elementos de carácter } & \text { medioambiental. } \\
\text { Referentes } & \text { arqueológicos y documentales. }\end{array}$ \\
\hline & & & $\begin{array}{l}\text { Manifestaciones correspondientes a los } \\
\text { diferentes movimientos estilísticos. }\end{array}$ \\
\hline & & Etnológico & $\begin{array}{l}\text { Elementos significativos y tradicionales que } \\
\text { explican el cambio social. }\end{array}$ \\
\hline & & $\begin{array}{l}\text { Científico- } \\
\text { Tecnológico }\end{array}$ & $\begin{array}{l}\text { Objetos e instrumentos que han contribuido a } \\
\text { la construcción del conocimiento científico. } \\
\text { Componentes tecnológicos e industriales }\end{array}$ \\
\hline
\end{tabular}


catalizadores del cambio socioeconómico. Inmuebles y paisajes asociados.

Holístico Consideración global e integrada de todas las manifestaciones anteriores.

Aidentitaria

No se establecen relaciones de identidad entre los elementos patrimoniales que aparecen en los materiales y un supuesto sujeto.

Individual

Reconocimiento del valor simbólico e identitario exclusivamente de aquellos

3. Escalas de identidad

Cultural-colectiva

Multiplicidad

identitaria

Sin conexión

4. Conexiones con

el entorno del Territorial

elemento

patrimonial
Interterritorial elementos patrimoniales cercanos y directamente relacionados con el individuo por su experiencia personal.

Reconocimiento del valor simbólico e identitario de elementos patrimoniales relativos a la cultura propia.

Integración de todos los elementos anteriores y valoración y respeto a la diversidad de identidades.

No se establecen conexiones entre patrimonio y entorno.

Se establecen conexiones entre patrimonio y entorno próximo.

Se establecen conexiones entre patrimonio y entorno próximo y otros ámbitos territoriales.

Tradicional

Sin participación de los estudiantes en el diseño de los objetivos, programas o sistemas de trabajo. El profesor protagoniza el proceso de forma exclusiva. Unidireccional.

Tecnológica

El papel del profesor consiste en la exposición y en la dirección de las actividades de la clase. El alumnado realiza de forma sistemática las actividades programadas.

5. Organización de Espontaneísta El papel del profesor es no directivo; coordina acción didáctica

Categoría II:

Investigativa la dinámica general de la clase como líder social y afectivo. Papel central y protagonista del alumnado (que realiza gran diversidad de actividades).

Modelo de

Enseñanza y comunicación

\begin{tabular}{|c|c|c|}
\hline \multirow{3}{*}{$\begin{array}{l}\text { 6. Papel de } \\
\text { emisores y } \\
\text { receptores en la } \\
\text { enseñanza y } \\
\text { difusión del } \\
\text { patrimonio }\end{array}$} & $\begin{array}{l}\text { Comunicación } \\
\text { unidireccional }\end{array}$ & $\begin{array}{l}\text { Inexistencia de interacción emisores- } \\
\text { receptores. Comportamiento pasivo de los } \\
\text { receptores. }\end{array}$ \\
\hline & $\begin{array}{l}\text { Comunicación } \\
\text { recíproca }\end{array}$ & $\begin{array}{l}\text { Interacción biunívoca entre emisor y receptor. } \\
\text { Comportamiento activo de los receptores }\end{array}$ \\
\hline & $\begin{array}{l}\text { Comunicación } \\
\text { multidireccional }\end{array}$ & $\begin{array}{l}\text { Interacciones múltiples. Todos pueden actuar } \\
\text { como emisores y receptores. }\end{array}$ \\
\hline \multirow{3}{*}{$\begin{array}{l}\text { 7. Nivel de } \\
\text { disciplinariedad }\end{array}$} & Unidisciplinar & de patrimonio. \\
\hline & Multidisciplinar & $\begin{array}{l}\text { Se trabajan varios tipos de patrimonio de forma } \\
\text { sumativa. }\end{array}$ \\
\hline & Interdisciplinar & $\begin{array}{l}\text { Se trabajan varios tipos de patrimonio de forma } \\
\text { sistémica. }\end{array}$ \\
\hline 8. Inte & Sin & $\begin{array}{l}\text { Se trabaja de forma predominante un tipo de } \\
\text { contenidos (Conceptuales; Procedimentales y }\end{array}$ \\
\hline
\end{tabular}

El alumnado aborda el problema como una investigación. Trabajo en torno a "problemas", con secuencia de actividades relativas al tratamiento de esos problemas. Papel activo del profesor como coordinador de los procesos. comportamiento pasivo de los

receptores en la enseñanza y

Comunicación

Comunicación Comportamiento activo de los receptores Interacciones múltiples. Todos pueden actuar como emisores y receptores. multidirecciona Se trabaja una sola tipologia de patrimonio. de forma sumativa. sistémica. contenidos (Conceptuales; Procedimentales y 


\begin{tabular}{|c|c|c|}
\hline \multirow[t]{3}{*}{ contenidos } & & Actitudinales). \\
\hline & Integración simple & $\begin{array}{l}\text { Se trabajan de forma predominante dos tipos } \\
\text { de contenidos relacionados (C-P; C-A; P-A). }\end{array}$ \\
\hline & Integración compleja & $\begin{array}{l}\text { Se trabajan los tres tipos de contenidos de } \\
\text { forma interrelacionada. }\end{array}$ \\
\hline \multirow{4}{*}{$\begin{array}{l}\text { 9. Contextualización } \\
\text { de los contenidos }\end{array}$} & Temporal & $\begin{array}{l}\text { Acentúa la cronología y los procesos históricos } \\
\text { de los elementos patrimoniales. }\end{array}$ \\
\hline & Espacial & $\begin{array}{l}\text { Acentúa la localización geográfica de los } \\
\text { elementos patrimoniales. }\end{array}$ \\
\hline & Social & $\begin{array}{l}\text { Acentúa las características sociales de la } \\
\text { comunidad. }\end{array}$ \\
\hline & Funcional & $\begin{array}{l}\text { Acentúa el uso y funcionamiento de los } \\
\text { elementos patrimoniales. }\end{array}$ \\
\hline \multirow{3}{*}{$\begin{array}{l}\text { 10. Finalidad de } \\
\text { la enseñanza }\end{array}$} & Academicista & $\begin{array}{l}\text { Conocimientos de hechos e informaciones de } \\
\text { carácter cultural, ilustrado y/o centrado en } \\
\text { aspectos anecdóticos. }\end{array}$ \\
\hline & $\begin{array}{l}\text { Práctica- } \\
\text { conservacionista }\end{array}$ & $\begin{array}{l}\text { Valor económico y/o sentimental en la vida } \\
\text { cotidiana. Conservación a ultranza de todos los } \\
\text { elementos que se consideren patrimonio. }\end{array}$ \\
\hline & Crítica & $\begin{array}{l}\text { Formación de ciudadanos comprometidos con } \\
\text { el desarrollo sostenible, que valoren y respeten } \\
\text { los elementos patrimoniales con alto valor } \\
\text { simbólico constitutivos de identidades. }\end{array}$ \\
\hline
\end{tabular}

Nota: Extraído de López-Arroyo (2017, pág. 118).

El paradigma seleccionado en el que se enmarca nuestra investigación es el constructivista y la metodología cualitativa, caracterizados por su naturaleza interpretativa, dinámica, participativa y múltiple, holística, construida y divergente. Los fenómenos culturales son más susceptibles de ser descritos y analizados desde el enfoque cualitativo. El principal objetivo científico que nos ocupa será la comprensión de esos aspectos planteados mediante la obtención de datos de las situaciones naturales, etnográficas y antropológicas. Se trata de interpretar los significados últimos atribuidos a cada una de las acciones realizadas por parte de los sujetos estudiados en el contexto escolar y patrimonial de Farmington, por medio de la articulación sistemática de las estructuras de significado subjetivo. Construyendo así, un conocimiento que estudia los aspectos esenciales de las vivencias y los objetos intencionales, bajo un carácter fenomenológico y naturalista (Husserl, 2012).

Se apuesta por una antropología comprensiva - interpretativa fundamentada en la noción de comprensión de Weber (1982 y 1984), en la que se busca los ideales motivadores de la acción. La realidad social debe ser entendida desde dentro. Otra de las preocupaciones clásicas superadas es la de la dualidad entre objetividad y subjetividad. Este problema se redefine en nuestro caso en términos de intersubjetividad. Volvemos así a una defensa del relativismo ideológico, consistente en que toda cultura tiene que ser analizada en términos de sí misma y ningún dato de la cultura puede ser aislado o abstraído de su contexto de producción con fines de comparación (Boas, 1920). Siguiendo los fundamentos de los estudios de casos de Stake (2007), la presente investigación anhela abarcar la complejidad de un caso de interés particular, las concepciones sobre patrimonio que poseen los estudiantes de FJH, para llegar a comprender en su conjunto las circunstancias más importantes que las determinan. Para la presente investigación de aula que planteamos, la i-a nos ayuda a descubrir un ambiente de aprendizaje del que se extraen nuevos significados. Las visiones patrimoniales particulares que se reflejan en el estudio son fiel reflejo de su contexto cultural e implementan y dotan de continuidad y armonía el universo que nos atañe. De la interacción entre profesor y alumnos se redescubren significados ocultos. En nuestro estudio desarrollamos los principios prácticos y emancipadores (Zuber-Skerritt, 1996); es decir, se potencia un pensamiento crítico para resolver problemas, conducidos por un profesor guía que propone, articula las ideas y analiza las repercusiones. Se alienta una vía emancipatoria dentro de un contexto social justo y democrático, con un activismo crítico a la vez que racional. Focalizamos el interés en posturas y visiones particulares sin perder las perspectivas de grupo (las excepciones son precisamente las que más información nos darán). Por ello, se presenta un estudio también de carácter antropológico, con una etnografía (Marcus y Fischer, 2004) de nuevos caminos que haga inteligible los procesos microsociales, que muestre igualmente las frontera culturales, manteniendo un claro sentido holístico e integrador de los aspectos contextuales. 


\section{Diseño de la investigación}

El presente trabajo parte de una interrogante que sustentará, junto con la búsqueda de respuestas, el camino de la investigación. Se plantea cómo un estudio de caso basado en las concepciones patrimoniales particulares del alumnado de $7^{\circ}$ curso de Farmington Junior High $(\mathrm{FJH})$, puede servir a su vez de propio mecanismo para el desarrollo profesional docente. El objetivo principal será indagar en esas concepciones, evidenciando mediante la aplicación de una didáctica patrimonial innovadora los pasos para alcanzar dicha progresión profesional (Figura 1). Tanto la formulación del problema y subproblemas de la investigación, como los objetivos principales y específicos de la misma se recogen sintetizados (Tabla 2).

\section{Figura 1}

Sintesis del planteamiento general de la investigación

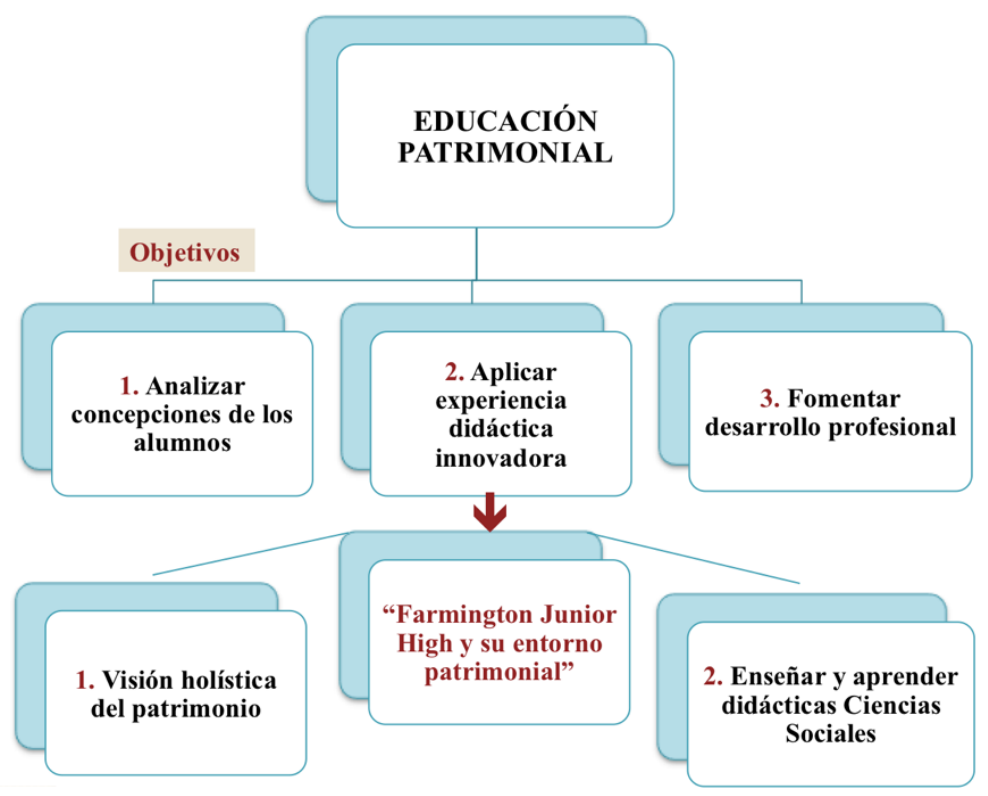


Tabla 2

Visión general de los problemas y objetivos de la investigación

\begin{tabular}{|c|c|}
\hline Problema general: & Objetivo general: \\
\hline $\begin{array}{l}\text { ¿Cómo un estudio de caso basado en las } \\
\text { concepciones patrimoniales particulares de los } \\
\text { alumnos puede servir a su vez de propio mecanismo } \\
\text { para el desarrollo profesional docente? }\end{array}$ & $\begin{array}{l}\text { Indagar en las concepciones que sobre el } \\
\text { patrimonio próximo tiene el alumnado de } \\
7^{\circ} \text { curso de Farmington Junior High, para } \\
\text { evidenciar mediante la aplicación de un } \\
\text { modelo de didáctica patrimonial } \\
\text { innovadora los pasos para alcanzar una } \\
\text { progresión notoria en el desarrollo } \\
\text { profesional docente. }\end{array}$ \\
\hline
\end{tabular}

Subproblemas

¿Qué características didácticas

1 presentan las experiencias publicadas tanto en España como en Estados Unidos referidas al aprovechamiento patrimonial próximo a los centros educativos?

¿Cuáles son las concepciones que

2 sobre el patrimonio más próximo tienen los alumnos de $7^{\circ}$ curso de Farmington Junior High?

3 ¿Cómo se puede enseñar el patrimonio cercano a los centros educativos desde un modelo de innovación educativa?

¿Cómo influye sobre las

4 concepciones de los estudiantes de Farmington Junior High desarrollar una experiencia patrimonial diseñada desde un modelo educativo innovador?

5 ¿Cómo se puede diseñar y llevar a la práctica una experiencia didáctica patrimonial desde un modelo innovador?

6 ¿De qué forma puede la didáctica del patrimonio ser una herramienta para el desarrollo profesional del docente?
Cuantificar y valorar las experiencias a nacionales e internacionales de aprovechamiento patrimonial próximas a los centros educativos ${ }^{3}$.

Detectar y analizar las concepciones b previas sobre patrimonio próximo que tiene el grupo de estudiantes seleccionados de Farmington Junior High.

c Desarrollar una experiencia de Educación Patrimonial innovadora basada en una visión holística sobre el patrimonio.

Analizar las nuevas concepciones d patrimoniales adquiridas por los estudiantes tras la intervención educativa realizada.

e Fundamentar una propuesta de Educación Patrimonial alternativa a los modelos tradicionales, con la intención de establecer una experiencia de referencia, especialmente útil para la educación formal y aprovechable también para la educación informal.

f Establecer unas pautas de progresión del desarrollo profesional docente vinculadas a la didáctica del patrimonio. 
En cuanto a los objetivos de la propuesta didáctica, los cuatro bloques de trabajo presentan unos que resultan generales y comunes para todos; posteriormente y de forma particular, se desarrollan junto con las actividades de presentación y de conclusión otros objetivos específicos. A continuación, se exponen los generales:
a) Conocer el entorno patrimonial próximo al centro educativo.
b) Crear conexiones interterritoriales con el entorno del elemento patrimonial.
c) Integrar los contenidos de una forma compleja y contextualizados de un modo funcional.
d) Trabajar el patrimonio de una forma interdisciplinar.
e) Organizar la acción didáctica de forma colaborativa e investigativa.
f) Favorecer una comunicación multidireccional en las dinámicas de trabajo.
g) Favorecer la multiplicidad identitaria.
h) Alcanzar una visión crítica en el alumnado.
i) Promover una visión holística del patrimonio.

\subsection{E1 escenario cercano como patrimonio}

Para contextualizar geográfica y socialmente la investigación resulta fundamental abordar los aspectos propios del entorno del centro educativo de FJH. Un contexto que influirá de forma decisiva en el diseño tanto de la propuesta didáctica desarrollada como a la hora de configurar las propias concepciones de los estudiantes en materia patrimonial. Utah se encuentra localizada en la región Oeste de los Estados Unidos, posee una población de 3 millones de personas aproximadamente, en una extensión de $219.887 \mathrm{~km} 2$. Tiene como capital la ciudad de Salt Lake City, eje de un importante centro financiero y comercial del país. Destaca también por su enorme atractivo natural, con sus cinco espectaculares Parques Nacionales. El otro gran atractivo que sitúa a esta región como foco del turismo deportivo de los Estados Unidos es su famosa nieve polvo considerada "the greatest snow on earth" (la mejor nieve del mundo) para la práctica de los deportes de invierno. Farmington tenía en el año 2019 una población estimada de 24 mil personas en una superficie de $25.8 \mathrm{~km} 2$. Es una ciudad donde los miembros de la Iglesia mormona poseen un importante peso en la comunidad local.

La experiencia se lleva a cabo en dos grupos del $7^{\circ}$ curso: Grupo 1 / Grupo 2 pertenecientes a FJH4. Alumnos entre 12 y 13 años de edad que estudian conmigo Historia de Utah en español dentro del Programa de Inmersión Dual que desarrolla el Estado de Utah (Utah Dual Language Immersion). Todos los estudiantes son americanos de nacimiento y mormones (resultará relevante para entender aspectos concretos de la experiencia), y no se encuentra entre ninguno de ellos padres de otras nacionalidades distinta a la propia norteamericana. FJH es la única escuela de Enseñanza Secundaria de la localidad, se encuentra entre las calles $150^{\circ}$ Sur y la 200 Oeste, en la parte histórica de la ciudad.

\subsection{Técnicas e instrumentos de análisis}

Se pasa a continuación a describir de forma somera las principales técnicas e instrumentos utilizados en la investigación. Se diseñan con el objetivo de que cada una de ellas ayude a avanzar en el proceso de interpretación de las concepciones de los estudiantes sobre su patrimonio próximo, y de que la conjunción de todas posibilite la triangulación de los resultados obtenidos tras su análisis (Figura 3). De las modalidades de observación que se realizan se puede denominar como "simple" aquella basada en hechos espontáneos sin interferencia del observador, siendo también de carácter "descriptiva" (Tabla 3).

\footnotetext{
${ }^{4}$ El primer grupo consta de 22 estudiantes y tendrá la función de validación del estudio. Aunque la dinámica de trabajo será la misma que en el Grupo 2, no será analizado de forma permanente con el sistema de categorías diseñado, puesto que se consideró que no aportaba datos diferenciadores respecto a los sujetos seleccionados, y se generaba además una cantidad de información que ralentizaba en exceso la investigación. Al ser el Grupo 1 la primera clase en el horario diario, la práctica de ensayo / error repercutirá en las posibles mejoras de la investigación del otro grupo. El Grupo 2, consta de 20 alumnos, diez chicos y diez chicas.
} 


\section{Figura 3}

Técnicas e instrumentos de análisis

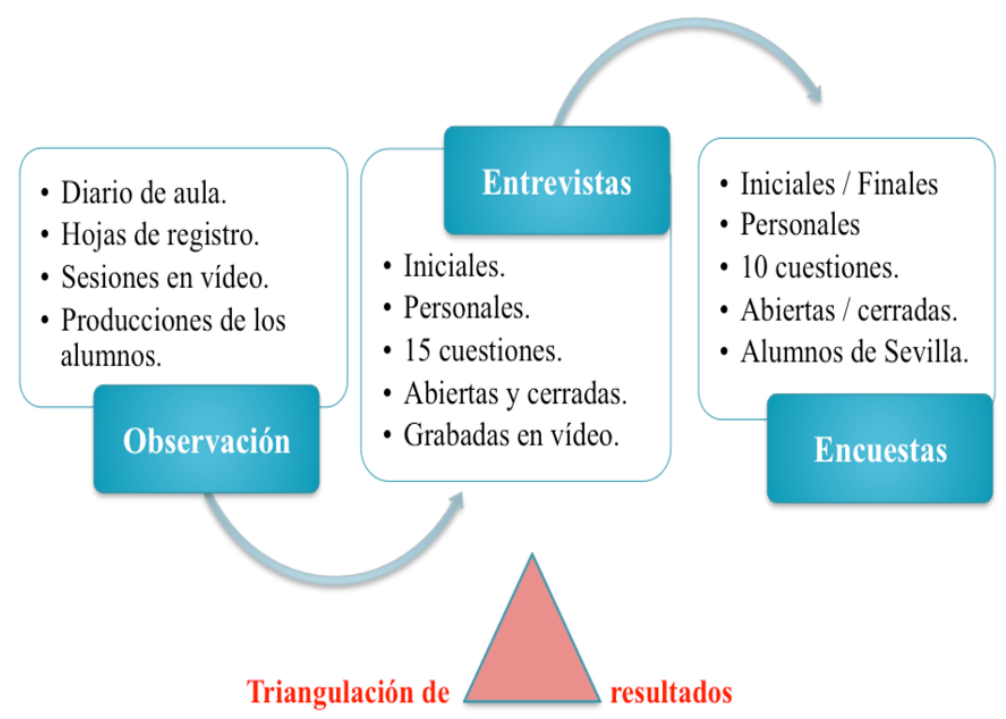

Tabla 3

Sintesis de las modalidades de observación

\section{Modalidades de observación}

\section{Diario de aula}

\section{Hojas de registro}

Sesiones de vídeo Producciones del alumnado

\section{Descripción}

Aspectos descriptivos más relevantes de cada una de las 30 sesiones desarrolladas en la investigación.

Registro de la actitud ante el trabajo diario de cada uno de los 20 estudiantes que componen el grupo clase. Una hoja por cada una de las sesiones.

Grabaciones de entrevistas iniciales y sesiones de clase.

Incluyen una gran variedad de producciones propias del alumnado: textos, vídeos, pósteres, lluvia de ideas, objetos, fotografías, etc. Se concluye con una muestra interactiva abierta al centro educativo.

Nota: Extraído de López-Arroyo (2017, pág. 125).

Entre estas modalidades se incluyen las entrevistas grabadas en vídeo que se realizan en el presente estudio, constan de 15 preguntas de respuestas abiertas y cerradas, semidirigidas por el propio investigador, como punto intermedio entre la entrevista propiamente dicha y la encuesta. La base de la misma son las encuestas inicial y final (Figura 4), a la que se le suman cinco nuevas cuestiones para detectar matices particulares y ahondar en determinados aspectos. Todas ellas resultarán claves para determinar la base de partida de la investigación.

\section{Figura 4}

Encuesta inicial sobre patrimonio

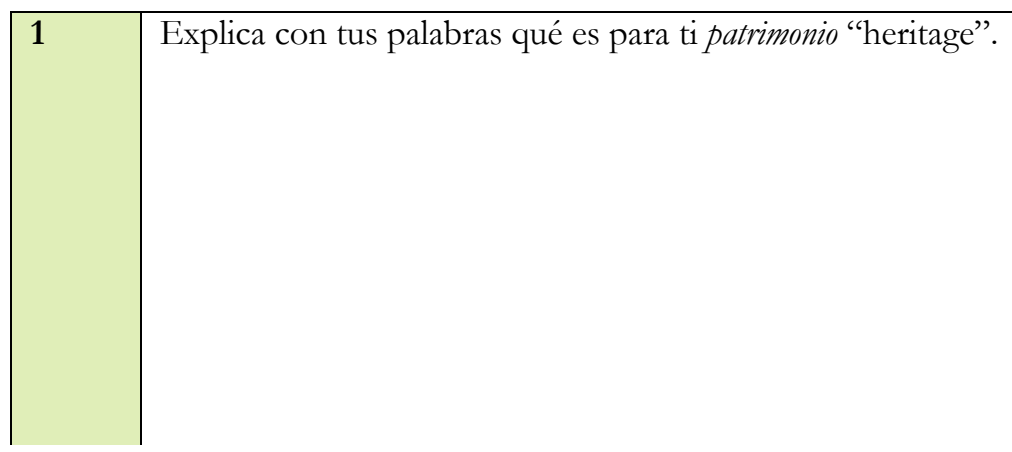


¿Cuáles de las siguientes imágenes relacionas con el concepto de patrimonio? Marca con una X.

2
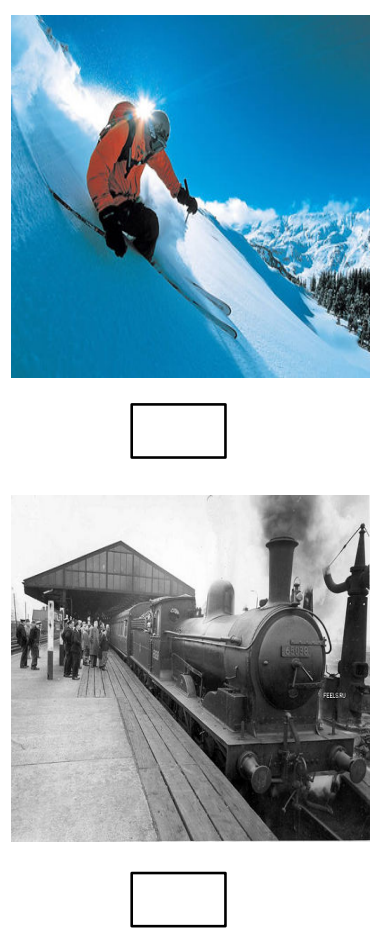
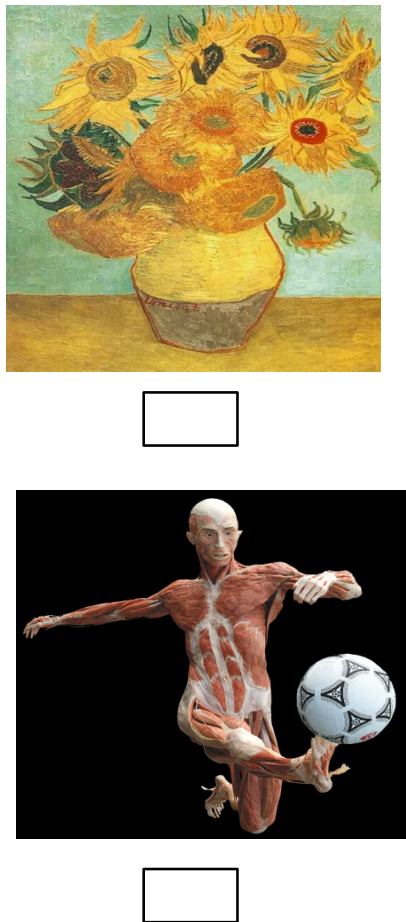
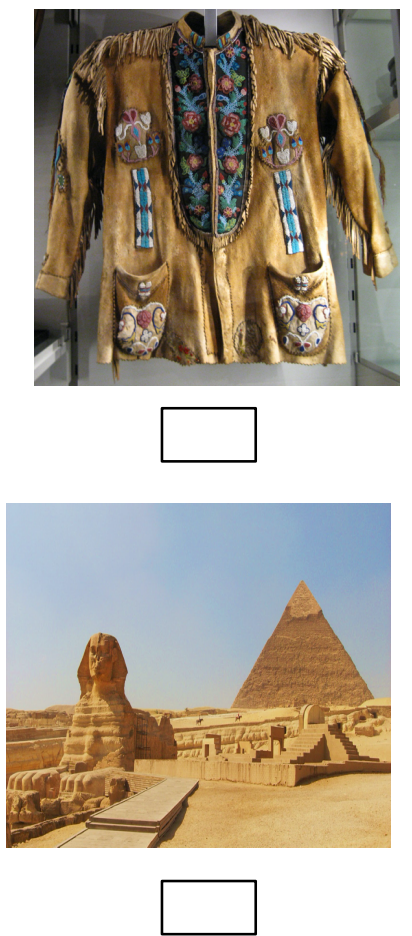

$3 \quad$ Señala 5 elementos diferentes que consideres patrimonio.

a) ¿Piensas que es importante estudiar el patrimonio?

Sí / No lo sé / No

b) Conocer el patrimonio es:

Muy importante / Bastante importante / Algo importante / No es importante

$5 \quad$ Explica por qué "sí" o por qué "no" es importante estudiar el patrimonio.

$6 \quad$ ¿Estudias algo relacionado con el patrimonio en la escuela?

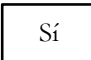

$$
\text { No }
$$

No lo sé

$7 \quad$ Si respondiste "sí" a la pregunta 6, explica qué estudias y en qué asignaturas.

8 ¿Qué te gustaría enseñar de Farmington a un amigo que viene a visitarte por primera vez?

$9 \quad ¿$ ¿Te gustaría hacer un proyecto en clase para estudiar aspectos del patrimonio de Farmington?

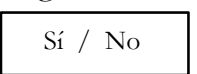

10 Explica qué propuesta te gustaría hacer para estudiar el patrimonio de Farmington. ¿Cómo lo harías y con qué objetivo?

Nota: Extraído de López-Arroyo (2017, págs. 134-135).

\section{Estructura y rasgos definitorios de una propuesta didáctica integral}

El núcleo de la investigación pasa por la propuesta patrimonial desarrollada dentro y fuera del centro educativo. Bajo el título de "Farmington Junior High y su entorno patrimonial" se organiza una dinámica de trabajo sencilla y práctica, estructurada en cuatro bloques, diez ámbitos de investigación y seis grandes actividades (Figuras 5 y 6), que dividieron la experiencia en una treintena de sesiones de trabajo. El sentido será conocer las concepciones que sobre el patrimonio cercano tiene el alumnado de entre doce y trece años de la mencionada escuela, y cómo a través de estas, y mediante el desarrollo de la propuesta de intervención se puede producir su progresión, facilitando además el desarrollo profesional como docente. 


\section{Figura 5}

Sintesis de desarrollo de "Farmington Junior High y su entorno patrimonial"

\begin{tabular}{cc}
\hline "FARMINGTON JUNIOR HIGH Y SU ENTORNO PATRIMONIAL" \\
(visión holística de patrimonio) \\
Actividad de \\
presentación
\end{tabular}

Nota: Extraído de López-Arroyo (2017, pág. 120). 


\section{Figura 6}

Mapa conceptual de los ámbitos de investigación de "Farmington Junior High y su entorno patrimonial"

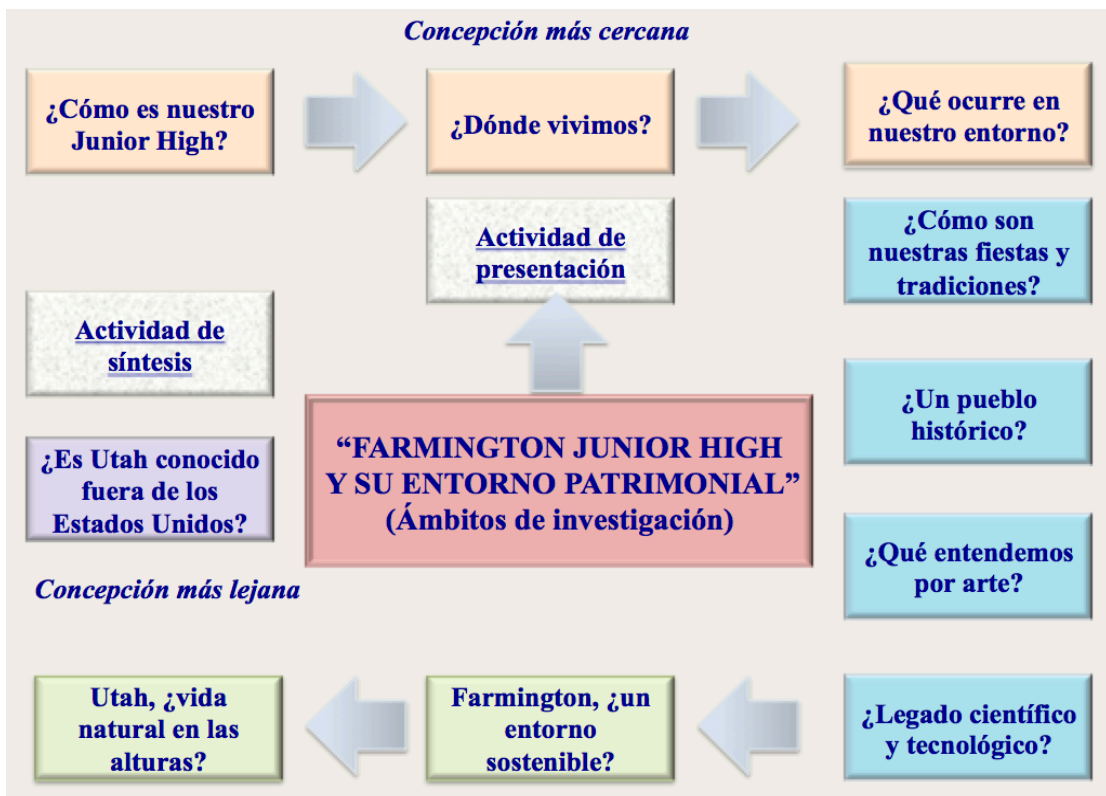

Nota: Extraído de López-Arroyo (2017, pág. 121).

La experiencia didáctica trata de conjugar todos los aspectos que resultan necesarios para definir una propuesta completa de esta índole (Tabla 4). En primer lugar, como ya se ha señalado, hay que tener en cuenta que su principal rasgo definitorio es su carácter puramente investigador. Por este motivo, se plantean interrogantes como ámbitos generales de la investigación. También aparecen cuestiones particulares al inicio de cada una de las actividades que los componen.

En cuanto a los contenidos, los definidos como conocimientos, habilidades, destrezas y actitudes son trabajados de forma interrelacionada, con lo que se persigue completar una acción educativa compleja y plenamente formativa. En la misma línea, todas las competencias claves están puestas en práctica en las actividades que configuran las dinámicas patrimoniales, y la evaluación de estas se basa en principios formativos y procesuales que se concretan en rúbricas de evaluación. 


\section{Tabla 4}

Relación de problemas, objetivos específicos, contenidos, competencias y evaluación de la propuesta didáctica realizada

\begin{tabular}{|c|c|c|c|c|}
\hline Problemas & Objetivos específicos & Contenidos & Competencias & Evaluación \\
\hline $\begin{array}{l}\text { Bloque I: } \\
\text { ¿Cómo es nuestro } \\
\text { Junior High? } \\
\text { ¿Dónde vivimos? } \\
\text { ¿Qué ocurre en } \\
\text { nuestro entorno? } \\
\text { Bloque II: } \\
\text { ¿Un pueblo histórico? } \\
\text { ¿Cómo son nuestras } \\
\text { fiestas y tradiciones? } \\
\text { ¿Qué entendemos por } \\
\text { arte? } \\
\text { ¿Legado científico y } \\
\text { tecnológico? } \\
\text { Bloque III: } \\
\text { Utah, ¿vida natural en } \\
\text { las alturas? } \\
\text { Farmington, ¿un } \\
\text { entorno sostenible? } \\
\text { Bloque IV: } \\
\text { ¿Es Utah conocido } \\
\text { fuera de los Estados } \\
\text { Unidos? } \\
\text { Actividad de } \\
\text { conclusión: } \\
\text { ¿Qué hemos } \\
\text { aprendido? } \\
\text { ¿Cómo podemos } \\
\text { difundirlo? }\end{array}$ & $\begin{array}{l}\text { Investigar sobre los aspectos naturales de nuestro entorno. } \\
\text { Diseñar una actuación de compromiso social con el } \\
\text { medioambiente. } \\
\text { Fomentar los valores de compromiso social con el entorno } \\
\text { patrimonial. } \\
\text { Favorecer la multiplicidad identitaria y las conexiones } \\
\text { interterritoriales de valor patrimonial. } \\
\text { Conocer las reflexiones e ideas finales de los alumnos sobre la } \\
\text { investigación yobre el concepto de patrimonio. } \\
\text { Sacar de forma conjunta conclusiones sobre el concepto de } \\
\text { patrimonio. } \\
\text { Promover la participación e implicación del profesor y alumnado } \\
\text { en la elaboración de una exposición conjunta sobre la } \\
\text { investigación. Hacer pública la investigación sobre el patrimonio } \\
\text { cercano a nuestra escuela. }\end{array}$ & 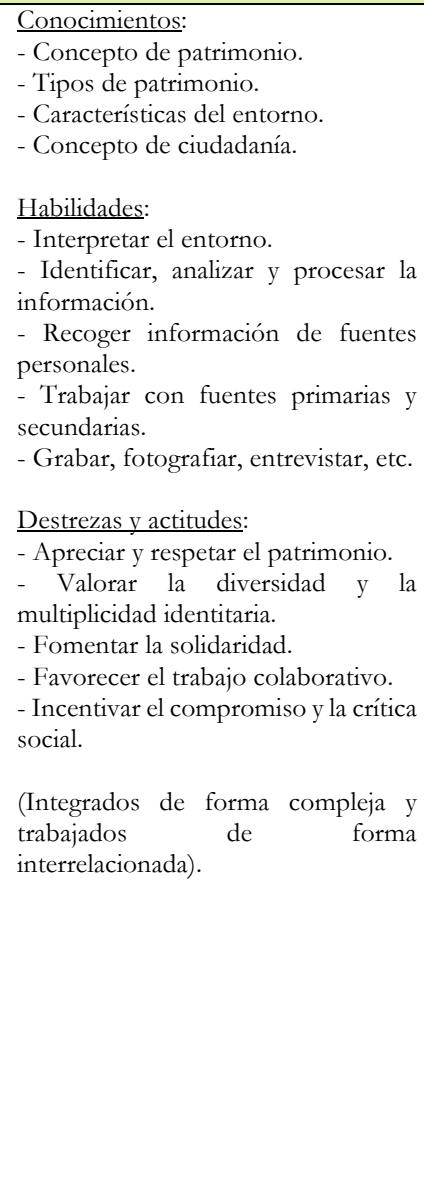 & $\begin{array}{l}\text { Competencias claves trabajadas y recogidas en } \\
\text { la legislación educativa española: } \\
\text { a) Competencia lingüística. } \\
\text { b) Competencia matemática y competencia } \\
\text { básica en ciencia y tecnología. } \\
\text { c) Competencia digital. } \\
\text { d) Aprender a aprender. } \\
\text { e) Competencias sociales y cívicas. } \\
\text { f) Sentido de iniciativa y espíritu emprendedor. } \\
\text { g) Conciencia y expresiones culturales. } \\
\text { Competencias trabajadas y recogidas en la } \\
\text { legislación educativa del Estado de Utah: } \\
\text { - Learner focused. } \\
\text { - Learner demonstrated. } \\
\text { - Learner led. } \\
\text { - Learner connected. } \\
\text { Marco educativo basado en competencias: } \\
\text { https://www.schools.utah.gov/file/93b6b3c0- } \\
\text { 85c7-47e5-9f1b-3677b1c9603b }\end{array}$ & $\begin{array}{l}\text { De forma general: } \\
\text { Es procesual y formativa. } \\
\text { Atiende a la necesidad de mostrar: } \\
\text { - Evidencias que sustenten logros. } \\
\text { - Una profundidad en estructuras y } \\
\text { razonamientos patrimoniales. } \\
\text { - Una aplicación de fórmulas y } \\
\text { principios creativos. } \\
\text { - Una sensibilización y compromiso } \\
\text { respecto a la consideración, } \\
\text { conservación y gestión del } \\
\text { patrimonio. } \\
\text { - Fundamentos críticos. }\end{array}$ \\
\hline
\end{tabular}




\subsection{Diario programado de sesiones}

Bajo el título de "Farmington Junior High y su entorno patrimonial" se muestra una dinámica de trabajo programada, detallada y original en la que las actividades diseñadas se utilizarán para canalizar la investigación. En total existen dieciséis fichas diseñadas a modo de guion que desarrollan todas las sesiones que configuran la propuesta didáctica, generando en su conjunto el denominado Diario de sesiones, que dota al profesor de un programa detallado de trabajo. Aparecen clasificadas en actividades iniciales, de desarrollo y de síntesis. De igual forma, incluyen la temporalización de cada sesión y todas las tareas necesarias que se deben llevar a cabo dentro de cada actividad. El diario también incluye la actividad de presentación y la actividad de conclusión. Por las limitaciones espaciales de la presente publicación se incluyen solo dos ejemplos, pertenecen tanto a bloques de contenido como a fases distintas (Tablas 5 y 6 ).

Tabla 5

Diario de sesiones. Ejemplo de actividades de desarrollo

\section{Actividad: "Detectives en la sombra". (E1 Husky Sabueso)}

Problema: ¿Cómo sería vuestro Junior High si ocuparas una posición diferente dentro de la comunidad educativa?

Fase de la actividad: De desarrollo. Trabajo de Temporalización: 1 hora de clase más trabajo campo.

Espacio para usar: Espacio escuela / Comunidad / Carácter de la actividad: Individual.

Ciudad de Farmington.

\section{Objetivos específicos:}

* Conocer e identificarse con el entorno más próximo: escuela y comunidad de Farmington.

* Implicar al alumno en una visión social y ciudadana.

\section{Desarrollo:}

* Tarea 1: El profesor sorteará cada una de las identidades entre los estudiantes, que asumirán uno de los siguientes roles: 3 dirección, 3 administración, 4 profesores, 2 consejeros (counselors), 2 padres, 3 personal de servicio, 1 político responsable de educación, 1 policía, 1 conductor de bus.

* Tarea 2: El profesor plantea a los estudiantes un juego de rol que consistirá en asumir esas personalidades como propias, visitando, estudiando cada identidad y transmitiendo sus preocupaciones. En la segunda mitad de la clase, los estudiantes saldrán del aula y entrevistarán a las personas con un cuestionario.

* Tarea 3: El profesor explica a los estudiantes que deben preparar, con el resultado de las entrevistas, un monólogo de unos dos minutos de duración para realizar un concurso en la siguiente sesión, donde transmitirán de forma divertida la personalidad asumida. Deben cuidar su español y actuar en primera persona como si fueran las personas entrevistadas.

Papel del alumno: Protagonista de todo el proceso. Con iniciativa, debe mostrarse interesado en conocer cada personalidad, trabajar la entrevista y conseguir información

\section{Contenidos:}


Conceptuales, procedimentales y actitudinales interrelacionados. precisa e interesante de cada identidad. Pensar cómo actuar de manera teatral en el monólogo de la próxima sesión.

Papel del profesor: Guía del proceso, orienta a los estudiantes. Organiza y transmite los pasos a seguir para realizar las entrevistas. Empieza la animación y motivación para la elaboración de buenos monólogos. Ejemplifica con alguna pequeña actuación cómo podrían representarlos.

Material y recursos: lápiz, cuaderno, cámara de fotos y de vídeo, grabadora. Ordenadores e internet. Nota: Extraído de López-Arroyo (2017, pág. 150).

Tabla 6

Diario de sesiones. Ejemplo de actividades de sintesis

Actividad: "Utah, un lugar en el mundo"

\section{Problemas:}

¿Conocen los estudiantes de España, Utah? ¿Qué elementos patrimoniales de Utah me gustaría que conocieran? ¿Podemos favorecer una ciudadanía universal descubriendo el patrimonio?

Fase de la actividad: Síntesis. Participación social. Temporalización: 2 horas.

Espacio para usar: Espacio clase / Aula de Carácter de la actividad: Grupo clase. informática.

Desarrollo:

* Tarea 1: Los estudiantes leen los correos electrónicos de los alumnos de España sobre su patrimonio.

\section{Objetivos específicos:}

* Fomentar los valores de compromiso social con el entorno patrimonial.

* Favorecer la multiplicidad identitaria y las conexiones interterritoriales de valor patrimonial.

\section{Contenidos:}

Conceptuales, procedimentales y actitudinales interrelacionados.

* Tarea 2: Los estudiantes visualizan los vídeos elaborados por los alumnos españoles sobre el entorno patrimonial de su colegio en Sevilla.

* Tarea 3: El profesor coordina una mesa redonda para que los estudiantes expresen sus opiniones sobre la actividad, basándose en las siguientes pregunta:

- ¿Qué elementos patrimoniales del entorno de la escuela de Sevilla os llaman más la atención?

- ¿Cuáles son las diferencias y parecidos con Farmington?

¿Qué se puede hacer para mejorar el patrimonio? - ¿Se pueden hacer cosas parecidas para mejorar el patrimonio en Sevilla y en Farmington?

- ¿Pensáis que descubriendo el patrimonio de lugares diferentes podemos favorecer una ciudadanía universal? ¿Por qué?

Papel del alumno: Protagonista de todo el proceso, debe reflexionar con profundidad sobre la experiencia realizada, aportar ideas y concluir sobre una visión holística y universal del patrimonio

Papel del profesor: Guía del proceso, favorece las ideas sobre la visión holística y universal del patrimonio. Papel de moderador en la mesa redonda. Refuerza de forma positiva al estudiante por su labor.

Material y recursos: lápiz, cuaderno y pizarra. Proyector. 


\subsection{Primeras evidencias de la investigación}

La propuesta nació como una necesidad educativa planteada en un estudio de caso concreto, y bajo la premisa fundamental de acercar desde un carácter puramente investigador al alumnado de $\mathrm{FJH}$ a su entorno patrimonial más próximo. Para su concepción se tuvo en cuenta todas las ideas previas trasmitidas por los estudiantes, recogidas especialmente en las encuestas iniciales y entrevistas realizadas en vídeo ${ }^{5}$ (Tablas 7 y 8), en su análisis posterior se procedió a cruzar las respuestas obtenidas con el sistema de categorías diseñado para tales efectos.

\section{Tabla 7}

Datos recogidos en la encuesta inicial

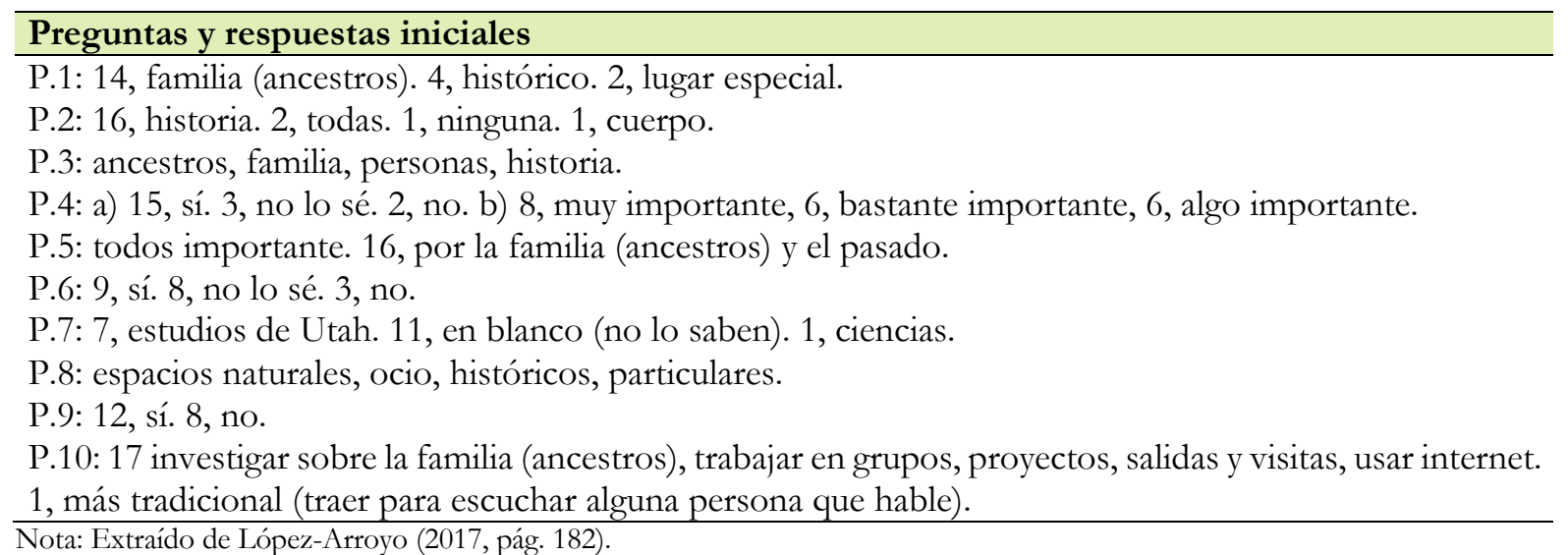

\section{Tabla 8}

Preguntas (1-2) y respuestas de las entrevistas iniciales grabadas en vídeo

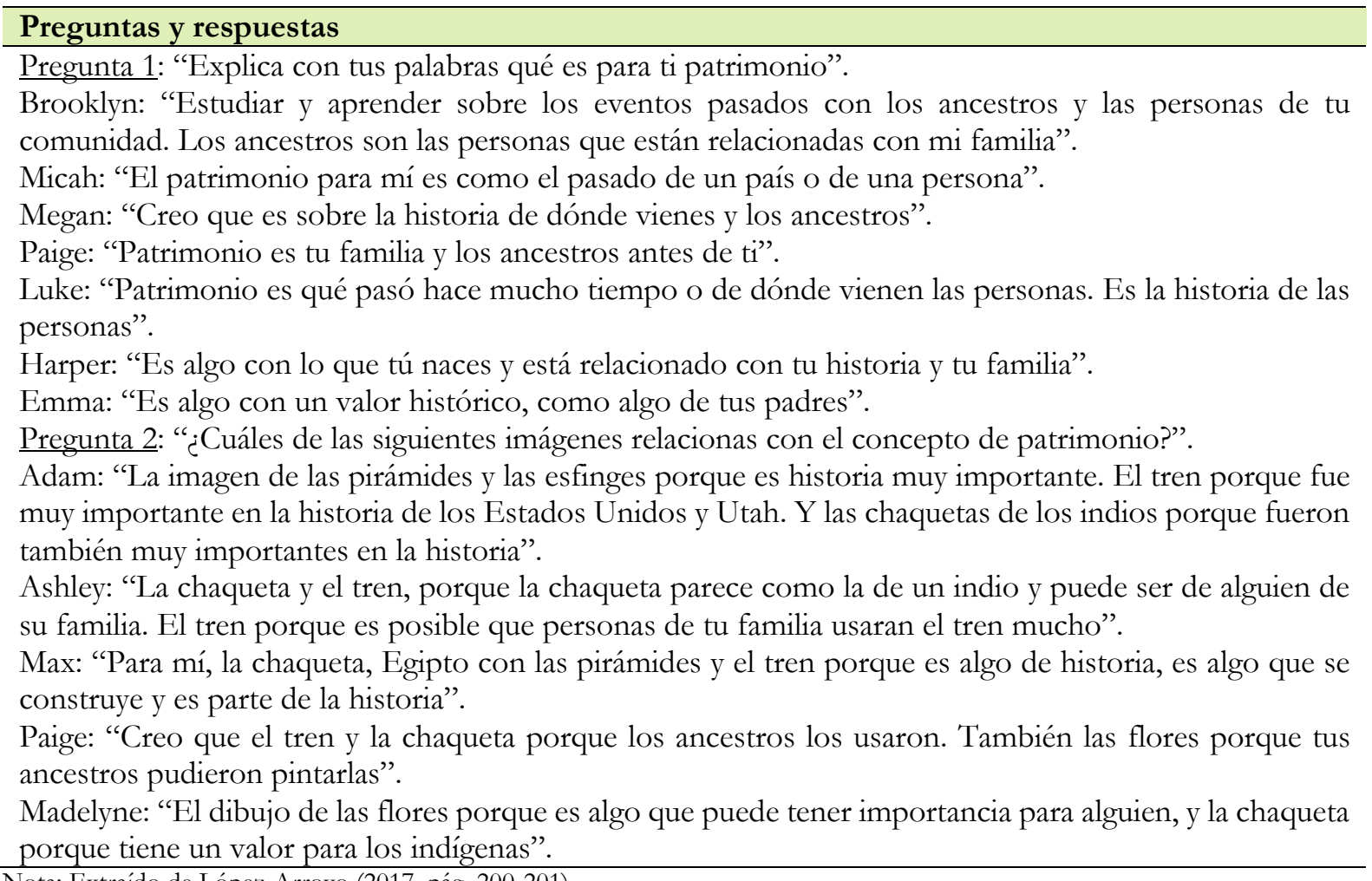
Nota: Extraído de López-Arroyo (2017, pág. 200-201).

\footnotetext{
${ }^{5}$ Las encuestas y las entrevistas en vídeo fueron realizadas a los 20 estudiantes del Grupo 2. Además, se grabaron otras sesiones por este medio a lo largo de la investigación; divididas en la Fase $1^{a}$ (previa al propio desarrollo práctico de los cuatro bloques) y Fase $2^{\mathrm{a}}$ (entre las actividades iniciales, de desarrollo y de síntesis). Sumando un total de 11 sesiones. Las hojas de registro y el diario de aula constan de 30 sesiones cada una.
} 
Entre muchos otros aspectos se detectó una visión parcial y limitada tanto del concepto de patrimonio como de entorno propio de la localidad. Los datos resultantes previos una vez cuantificados y analizados dejaron varias ideas que marcan el inicio de la investigación y abren unas posibilidades de trabajo óptimas para alcanzar los objetivos diseñados. El alumnado valora y siente como propia su localización colectiva, concretando su identidad en aspectos históricos y familiares (P.1), arraigada en la clara influencia que tiene la Iglesia mormona en la localidad y en la importancia que atribuye a dichos aspectos. Esta fuerte idea de pertenencia a su localidad de Farmington supone un excelente marco para fomentar y asentar posteriores concepciones patrimoniales más amplias (Categoría I). Por otra parte, el alumnado muestra de forma natural una tendencia investigadora (P.10); quieren lanzarse a la calle, preguntar, indagar fuera del aula, ver edificios, etc., lo que conecta a la perfección y refuerza aún más la idea de aprender investigando que se propone desde estas líneas.

\section{Evaluación y resultados finales}

Para la evaluación de la experiencia se tuvieron en cuenta tanto aspectos generales como específicos de la misma. Se señalan a continuación los aspectos más destacados de la evaluación en su relación con las nuevas concepciones adquiridas por el alumnado; y por otro lado, el análisis de los logros vinculados al propio desarrollo profesional. La intención última es limitar el grado de subjetividad, posibilitando una investigación transparente y rigurosa. A lo largo de todo el proceso del análisis se fueron valorando, tanto de forma particular como agrupada, los distintos instrumentos de recogida de información: encuestas (Tabla 9), grabaciones en vídeo, hojas de registro, diario de sesiones, materiales producidos y exposición final.

Tabla 9

Datos recogidos en la encuesta final

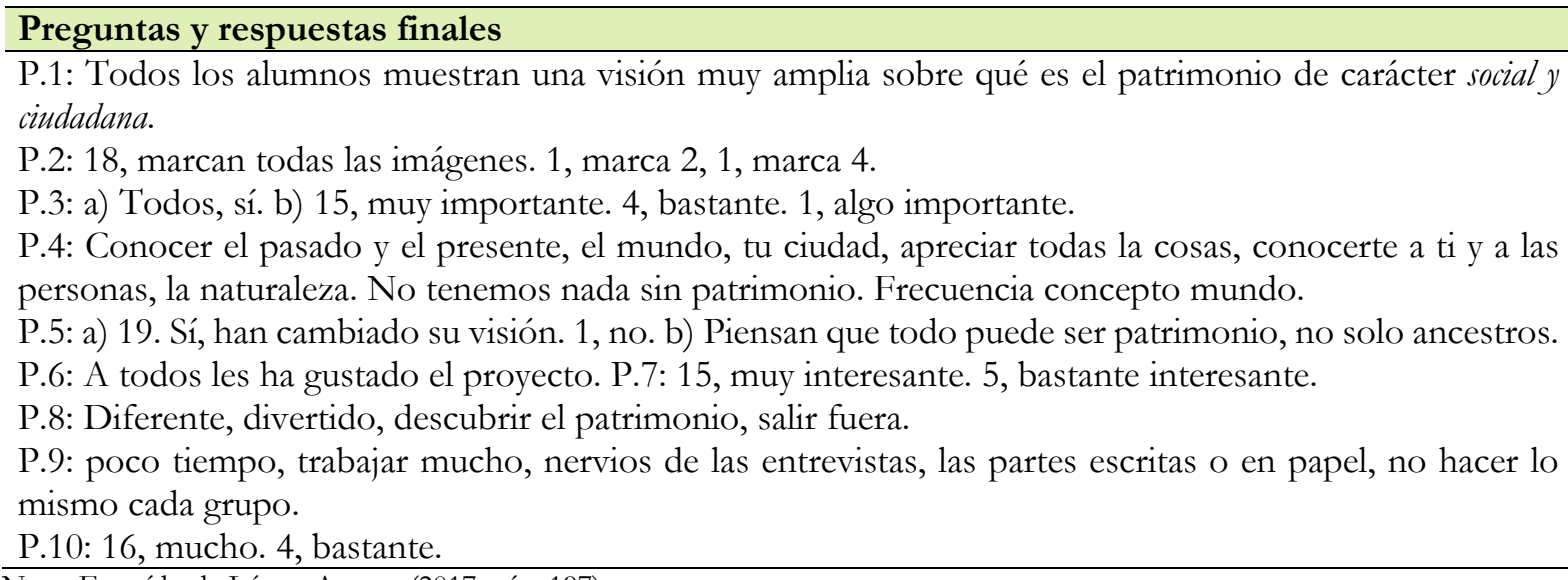
Nota: Extraído de López-Arroyo (2017, pág. 197).

Por la gran cantidad de evidencias recogidas solo se pretende presentar a modo de síntesis una visión global del proceso de análisis. En primer lugar, hay que señalar una clara evolución de las concepciones de los estudiantes desde los momentos iniciales hasta el final de la propia experiencia (Tabla 10). La tipología patrimonial holística focaliza el crecimiento y la trasformación de las concepciones; la multiplicidad identitaria y las conexiones interterritoriales de los elementos patrimoniales, favorecidas por la interacción con otros destinos trabajados, redimensionan sus valores. De esa forma, al inicio de la investigación las evidencias aportadas por los protagonistas definieron un universo patrimonial limitado y centrado en pautas patrimoniales cerradas. La especificidad del concepto de patrimonio aportado por los estudiantes sirvió a su vez para entender los preceptos culturales del contexto histórico-social de la localidad de Farmington, donde aspectos concretos como la religión, la familia o la historia, determinan la identidad particular de la comunidad. Por su peso vertebrador, la presente investigación conserva y protege dichos indicadores referidos a la perspectiva sobre el patrimonio, pero a su vez adhiere otros indicadores que resultan fundamentales para el crecimiento de las concepciones. El reconocimiento de la propia idiosincrasia patrimonial resultó clave, como punto de partida del trabajo de sensibilización y detección de los bienes próximos al centro educativo. Los cambios producidos no se pueden entender sin la intervención desarrollada a partir de las actividades presentadas en los cuatro Bloques de contenidos. De igual forma, 
tampoco hay que olvidar los momentos previos recogidos en la Actividad de presentación y los últimos de la Actividad de conclusión. Todas y cada una de las variables sufrieron una evolución en positivo; es decir, el alumnado después de la experiencia presenta un universo patrimonial infinitamente más rico y plural que al inicio del proceso. Este aspecto, se ve especialmente en las encuestas, también en la comparativa de los argumentos dados en las entrevistas iniciales en vídeo y en resto de las sesiones de trabajo grabadas con ese mismo medio. Reflexiones tales como: "Patrimonio son todas la cosas importantes que forman parte de tu vida y de la vida de los demás"; o "Creo que el patrimonio está en todas partes, la música que escuchas, los edificios en los que estás, etc. Pensé que patrimonio era un tema pequeño pero ahora sé que no lo es. Patrimonio es casi todo" (Extraído de López-Arroyo, 2017, pp. 184 y 185), argumentan el éxito de la propuesta.

Tabla 10

Evolución en los indicadores del sistema de categorías en momentos iniciales y finales de la investigación

\begin{tabular}{|c|c|c|}
\hline \multirow[b]{2}{*}{ Variables } & \multicolumn{2}{|c|}{ Indicadores detectados } \\
\hline & $\begin{array}{c}\text { Encuestas iniciales / entrevistas } \\
\text { iniciales }\end{array}$ & Actividades de síntesis \\
\hline $\begin{array}{l}\text { 1. Perspectiva sobre } \\
\text { el patrimonio. }\end{array}$ & Histórica / Simbólico-identitaria & $\begin{array}{l}\text { Simbólico-identitaria / Social- } \\
\text { ciudadana }\end{array}$ \\
\hline $\begin{array}{l}\text { 2. Tipos de } \\
\text { patrimonio. }\end{array}$ & Natural-Histórico-Artístico & Holístico \\
\hline $\begin{array}{l}\text { 3. Escalas de } \\
\text { identidad. }\end{array}$ & Individual / Cultural-colectiva & Multiplicidad identitaria \\
\hline $\begin{array}{l}\text { 4. Conexiones con el } \\
\text { entorno del elemento } \\
\text { patrimonial. }\end{array}$ & Territorial & Interterritorial \\
\hline $\begin{array}{l}\text { 5. Organización de } \\
\text { acción didáctica. }\end{array}$ & Investigativa & Investigativa \\
\hline $\begin{array}{l}\text { 6. Papel de emisores y } \\
\text { receptores en la } \\
\text { enseñanza y difusión } \\
\text { del patrimonio. }\end{array}$ & Comunicación recíproca & Comunicación multidireccional \\
\hline $\begin{array}{l}\text { 7. Nivel de } \\
\text { disciplinariedad. }\end{array}$ & Unidisciplinar & Interdisciplinar \\
\hline $\begin{array}{l}\text { 8. Integración de } \\
\text { contenidos. }\end{array}$ & Sin integración & Integración compleja \\
\hline $\begin{array}{l}\text { 9. Contextualización } \\
\text { de los contenidos. }\end{array}$ & Temporal / Social & Funcional \\
\hline $\begin{array}{l}\text { 10. Finalidad de la } \\
\text { enseñanza. }\end{array}$ & Academicista & Crítica \\
\hline
\end{tabular}

Nota: Extraído de López-Arroyo (2017, pág. 225).

En segundo lugar, hay que subrayar la trascendencia de las hojas de registro y del diario de aula, imprescindibles para llegar a comprender la plena participación y el compromiso de los estudiantes desde el inicio mismo del proyecto de investigación. A buen seguro existirán múltiples vías para alcanzar la consecución de los objetivos marcados con anterioridad, pero cuando estos se logran desde el convencimiento y la firme voluntad de sus protagonistas, las sensaciones recogidas resultan también imprescindibles en la propia concienciación y participación activa sobre el patrimonio. En general, entorno al $80 \%$ o $90 \%$ del alumnado cumplen positivamente con los 10 indicadores susceptibles de ser evaluados en cada una de las sesiones de trabajo. No resulta fácil distinguir entre los ítems más frecuenciados; aún así, se podría destacar el número 1 (participa activamente en las dinámicas), o el 5 (aporta ideas en general).

En tercer lugar, la suma de todos los materiales presentados ${ }^{6}$ aportan una clara visión global e integradora sobre los bienes del entorno de FJH (Tabla 11). Se constata una perspectiva interdisciplinar (Didáctica de las Ciencias Sociales y Ciencias Experimentales) fruto de la aplicación original y práctica por

\footnotetext{
${ }^{6}$ Los materiales presentados por los estudiantes son sin duda alguna los aspectos más destacados de la experiencia didáctica. Por las limitaciones propias de la publicación resulta imposible que tengan aquí cabida. Nos remitimos para su disfrute a la obra ya referenciada (López-Arroyo, 2017).
} 
parte de los estudiantes, con una organización de la acción didáctica puramente investigativa. Se supera definitivamente la concepción fragmentada y reduccionista del patrimonio referida en los momentos previos.

Tabla 11

Sumario de materiales y evidencias producidos por el alumnado

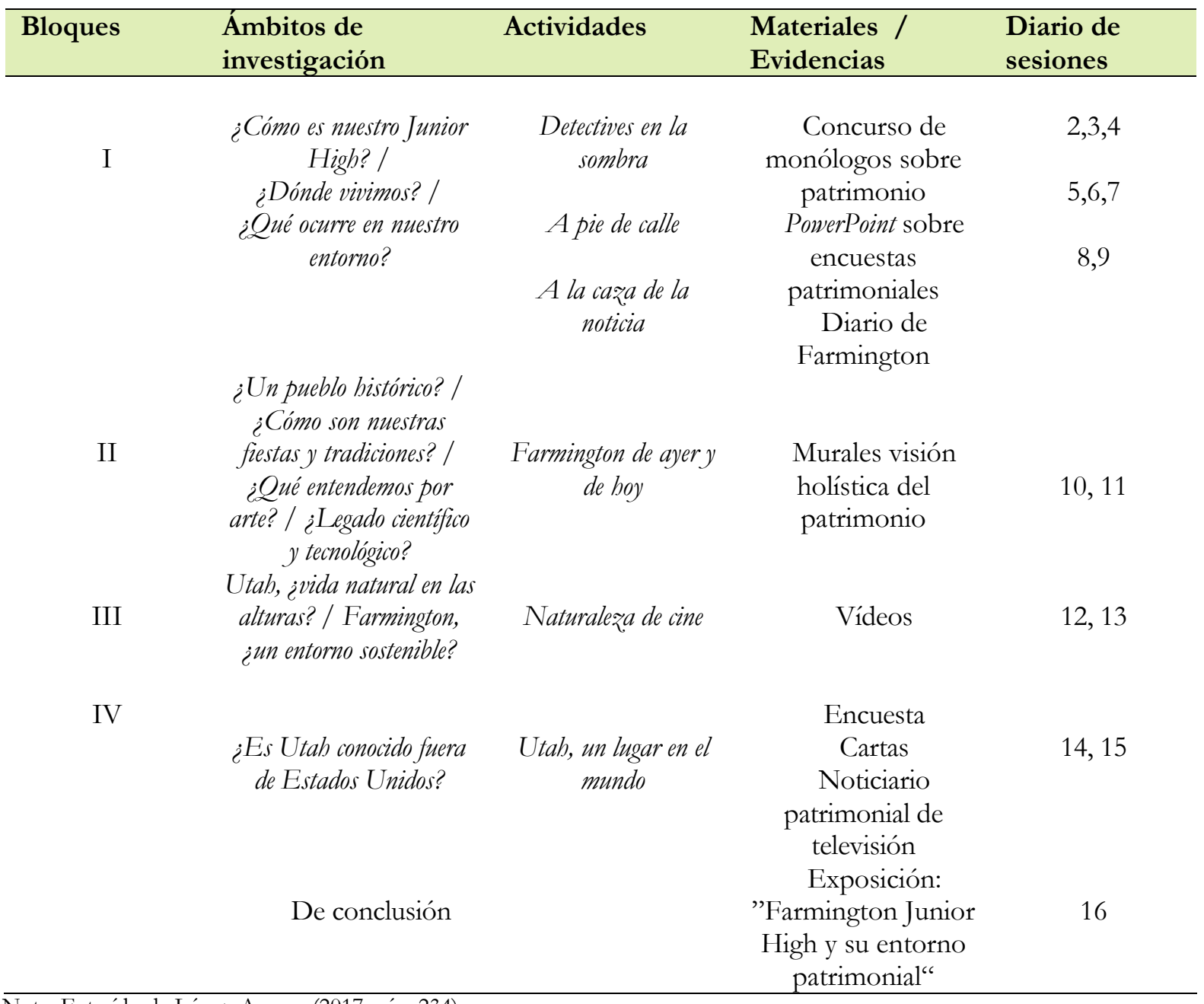

Nota: Extraído de López-Arroyo (2017, pág. 234).

En buena medida, consecuencia de la multiplicidad en las aplicaciones prácticas de la didáctica del patrimonio, se enumeran a continuación los resultados más relevantes obtenidos del proceso. Podemos clasificarlos en:

a) Resultados directos del análisis de la investigación.

Se logró mediante la ejecución de técnicas e instrumentos de investigación detectar y contrastar a través de la rejilla de observación diseñada las concepciones particulares que sobre patrimonio poseen nuestros estudiantes.

Se consiguió enriquecer el Concepto de patrimonio con sus distintas variables señaladas.

Se alcanzó un Modelo de enseñanza y comunicación deseable, en relación a las variables apuntadas.

b) Resultados pedagógicos. de FJH.

Se pudo situar el patrimonio en el foco de interés de los estudiantes y en el de la comunidad educativa

Se aprovechó de manera muy eficiente el entorno patrimonial próximo de Farmington Junior High, constituyéndolo en herramienta educativa y principio activo de la participación ciudadana.

Se logró, a partir de los centros de interés de los estudiantes, diseñar y llevar a la práctica una dinámica pedagógica de carácter innovador y fundamentada en el aprender investigando. 


\subsection{El desarrollo profesional vinculado a la didáctica patrimonial.}

Los aspectos relacionados con el desarrollo profesional docente derivados de la presente experiencia suponen una parte muy destacada del trabajo. En este punto se tratará de evidenciar cómo dicha experiencia contribuyó a mi progreso en las aulas y de qué manera puede hacerlo al tuyo. Para ello, nos basaremos en la propia experiencia diseñada y en un conjunto de sensaciones concretas derivadas de su aplicación. Para finalmente afirmar que el modelo didáctico seleccionado y aplicado en esta investigación contribuye a una mejora sustancial en lo profesional. No se trata de una cuestión baladí, si tenemos en cuenta que, además del plano estrictamente particular, existe una repercusión educativa directa y trascendental entre un profesor preocupado por su desarrollo profesional y el alumnado con el que trabaja, produciéndose una relación de retroalimentación que beneficia a ambas partes del proceso de enseñanza y aprendizaje. El sistema de categorías diseñado para nuestra investigación va a ser el elemento base utilizado para delimitar y señalar los diferentes indicadores que muestren una escala superior de progresión en la docencia, presentando en consecuencia un reflejo en la misma propuesta didáctica o en otros instrumentos usados para la recogida de la información. De esa forma, quedarán vinculados a la Concepto de patrimonio (Categoría I) o al Modelo de enseñanza y comunicación (Categoría II). (Tabla 12).

Tabla 12

Rejilla de observación con indicadores vinculados al desarrollo profesional

\begin{tabular}{|c|c|c|c|}
\hline $\begin{array}{l}\text { Categoría } \\
\\
\text { Categoría I: } \\
\text { Concepto de } \\
\text { patrimonio }\end{array}$ & $\begin{array}{l}\text { Variables } \\
\text { 1. Perspectiva } \\
\text { sobre patrimonio. }\end{array}$ & Indicador & Evidencias $^{7}$ \\
\hline \multirow{9}{*}{$\begin{array}{l}\text { Categoría I: } \\
\begin{array}{l}\text { Concepto de } \\
\text { patrimonio }\end{array}\end{array}$} & \multirow{2}{*}{$\begin{array}{l}\text { 1. Perspectiva } \\
\text { sobre patrimonio. }\end{array}$} & \multirow{2}{*}{$\begin{array}{l}\text { Simbólica } \\
\text { identitaria } \\
\text { Social-ciudadana }\end{array}$} & \multirow{7}{*}{$\begin{array}{l}\text { Actividad de presentación de la } \\
\text { propuesta didáctica. } \\
\text { Actividades diseñadas en la } \\
\text { propuesta vinculadas al entorno. } \\
\text { Propuesta global e integrada con } \\
\text { todas las tipologías patrimoniales. } \\
\text { Proyección internacional en } \\
\text { actividades de la propuesta. } \\
\text { Propuesta fundamentada en el } \\
\text { entorno de la escuela. } \\
\text { Actividades que ponen al } \\
\text { alumnado en contacto con otras } \\
\text { realidades patrimoniales (Sevilla). }\end{array}$} \\
\hline & & & \\
\hline & \multirow{5}{*}{$\begin{array}{l}\text { 2. Tipos de } \\
\text { patrimonio. } \\
\text { 3. Escala de } \\
\text { identidad. } \\
\text { 4. Conexiones con } \\
\text { el entorno del } \\
\text { elemento } \\
\text { patrimonial. }\end{array}$} & \multirow{5}{*}{$\begin{array}{l}\text { Holístico } \\
\text { Multiplicidad } \\
\text { identitaria } \\
\text { Territorial } \\
\text { Interterritorial }\end{array}$} & \\
\hline & & & \\
\hline & & & \\
\hline & & & \\
\hline & & & \\
\hline & $\begin{array}{l}\text { 5. Organización } \\
\text { didáctica. }\end{array}$ & Investigativa & $\begin{array}{l}\text { Propuesta basada en ámbitos de } \\
\text { investigación. }\end{array}$ \\
\hline & $\begin{array}{l}\text { 6. Papel de } \\
\text { emisores y } \\
\text { receptores en la } \\
\text { enseñanza y }\end{array}$ & $\begin{array}{l}\text { Comunicación } \\
\text { multidireccional }\end{array}$ & $\begin{array}{l}\text { El propio alumnado, la } \\
\text { comunidad de Farmington, los } \\
\text { estudiantes de Sevilla, etc., actúan } \\
\text { como emisores y receptores. }\end{array}$ \\
\hline
\end{tabular}

Categoría II:

Modelo de

enseñanza y comunicación
2. Tipos de patrimonio. 3. Escala de difusión del patrimonio.

7. Nivel de disciplinariedad.

8. Integración de contenidos.

Integración compleja

9.

Contextualización de los contenidos.
Social

Funcional
Ámbitos de investigación de la propuesta relacionados con todos los tipos de patrimonio. Trabajados de forma sistémica. Actividades de la propuesta, trabajan los tres tipos de contenidos relacionados. Fases de sintesis de cada actividad del Diario de sesiones.

\footnotetext{
${ }^{7}$ En la columna de la tabla referida a las evidencias solo se apuntan (con una finalidad práctica) algunos de los aspectos generales y relevantes que guardan una relación directa con los indicadores marcados. Existen como es lógico una gran cantidad de referencias concretas que ratifican los valores definidos dentro de la propuesta didáctica patrimonial.
} 
10. Finalidad de la enseñanza.
Fases de desarrollo y de sintesis de cada una de las actividades del diario de sesiones. Actividad de conclusión de la propuesta.

Nota: Extraído de López-Arroyo (2017, pág. 167).

Crítica

La rejilla de observación muestra indicadores que marcan dentro del sistema de categorías diseñado unas cotas evidentes de progresión. Si, como pensamos puede establecerse una hipótesis de progresión del desarrollo profesional respecto a la enseñanza del patrimonio, podría afirmarse que los datos arriba indicados definen el nivel más alto, referido tanto al Conocimiento sobre el patrimonio, como al Conocimiento sobre la enseñanza del patrimonio (metodología, contenidos y metas). La propuesta en su conjunto puede definirse así como comprensiva, significativa y motivadora, estableciendo unas unidades didácticas de índole constructivista, caracterizadas por una enseñanza de corte social e investigativa. Integrando los contenidos y con el claro objetivo de formar a ciudadanos comprometidos y activos en la defensa del patrimonio. Todo ello, me sitúa en una fase actual que contribuye a un estado de complejidad y reflexión continua respecto al conocimiento de la didáctica del patrimonio, aspecto este último que facilita una predisposición como docente a indagar en nuevas posibilidades de innovación y de desarrollo profesional. Otras evidencias relacionadas con los indicadores claves apuntados son los resultados obtenidos mediante las técnicas e instrumentos aplicados en la investigación, y que guardan una relación directa y exacta con la evaluación personal de la propuesta de "Farmington Junior High y su entorno patrimonial".

$\mathrm{Al}$ margen de la gran cantidad de datos recabados e interpretaciones de los mismos, existe un conjunto de sensaciones gratificantes que no aparecerán de forma explicita, pero que deben ser mencionadas en su relación con el desarrollo profesional porque resultan también parte fundamental de lo vivido. La satisfacción personal que los estudiantes me trasladaron en cada jornada, junto con la ilusión expresada por realizar un proyecto que siempre consideraron como "diferente", atractivo y significativo para ellos, fue sin duda la nota predominante a lo largo de toda la propuesta desarrollada. En ese sentido, la triangulación de resultados obtenidos con la evaluación personal y continua como docente, la evaluación de los alumnos (a través de la fase de síntesis de cada actividad, rúbricas, o en las encuestas finales del proyecto) y el análisis conjunto de los resultados obtenidos en cada una de las producciones realizadas, otorgan a la propuesta didáctica de conocimiento del entorno patrimonial una influencia decisoria en el desarrollo profesional del profesor.

\subsection{Discusión de resultados}

Nuestro trabajo remarca la simbiosis perfecta entre patrimonio y territorio como instrumento de participación ciudadana en la vida publica, tan necesaria en la actualidad, gestada desde el compromiso con la cultura propia como con la de los demás. El resultado es una sociabilización del patrimonio como referente de identidad, lo que se traduce en una incalculable rentabilidad social. El hecho de que la investigación muestre conexiones entre patrimonio, territorio, emociones y comunidad, la relaciona con estudios tan actuales como los que vinculan la inteligencia territorial con la inteligencia emocional, siendo el patrimonio y las acciones educativas unos vehículos excepcionales para un desarrollo social, sustentable y comprometido con la comunidad (Trabajo y Cuenca, 2017; Riveiro, López-Álvarez y López-Facal, 2017; Santacana y Martínez, 2018; Munilla y Marín, 2020).

La principal limitación del estudio de caso es la escasa posibilidad de universalizar los resultados pero ofrece en cambio la posibilidad de aplicar los parámetros desarrollados a otros centros educativos tanto en España como fuera de ella. Cada experiencia en el entorno escolar demuestra un universo diferente y plural, lleno de pequeños matices que resultaría conveniente someterlos a la búsqueda de afinidades. La idea última debe ser investigar y evidenciar las posibilidades reales que posee el patrimonio como instrumento de primer orden en la formación de una ciudadanía crítica, bajo los principios de la universalidad. De igual forma, habría que analizar cómo evoluciona el concepto de patrimonio a lo largo de las distintas etapas educativas, y hasta qué punto influye la escuela y el entorno social en la configuración de dicha identidad. En esa línea, hay que abrir nuevas vías referidas a los dos principales sujetos vinculados a la didáctica patrimonial escolar; por una parte, otorgando un mayor grado de participación e implicación a nuestros estudiantes con el objetivo de poner en práctica y evaluar su propia capacidad para transformar la realidad. Y por otra, continuar indagando respecto a la relación existente entre patrimonio y la mejora profesional docente. 


\section{Reflexiones finales}

El patrimonio resulta clave para la construcción de la identidad, se constituye en un ámbito imprescindible para el crecimiento formativo de la ciudadanía. Todo cuanto nos rodea puede estar sujeto a ser considerado patrimonio pero únicamente lo es aquello que ha pasado por lo que denominamos proceso de patrimonialización. Para ello, la Educación Patrimonial adquiere una especial relevancia en el ámbito escolar. Se necesitan experiencias de aula que puedan servir de guías para un profesorado que cada vez más demanda estas dinámicas. La posibilidad de que haya sido llevada a la práctica y aporte resultados verificados científicamente, sitúa a "Farmington Junior High y su entorno patrimonial" con un valor referencial, constituyéndose como un modelo exportable a otros contextos. Los resultados demuestran las enormes posibilidades que tiene esta didáctica en la formación de los estudiantes y en el desarrollo profesional del profesorado.

\section{Referencias}

Aguirre, I (2012). Retos de la investigación en Educación Patrimonial. I Congreso Internacional de Educación Patrimonial. Ministerio de Educación, Cultura y Deporte.

Boas F. (1920). The Methods of Ethnology. American Anthropologist. New Series, 22(4), 311-321. Recuperado de www.jstor.org/stable/660328.

Cañal, P., Pozuelos, F. J. y Travé, G. (2005). Proyecto Curricular Investigando Nuestro Mundo. Descripción General y Fundamentos. Díada.

Coma, J. y Santacana J. (2010). Ciudad educadora y patrimonio. "Cookbook of heritage". Trea.

Cuenca, J. M. (2014). El papel del patrimonio en los centros educativos: hacia la socialización patrimonial. Tejuelo, 19, 76-96.

Cuenca, J. M., Martín, M., Estepa, J. (2020). Buenas prácticas en educación patrimonial: análisis de las conexiones entre emociones, territorio y ciudadanía. Aula abierta, 49(1), 45-54.

Fontal, O. (2007) El patrimonio cultural del entorno próximo: un diseño de sensibilización para secundaria. Enseñanza de las ciencias sociales: revista de investigación, 6, 31-48.

Husserl, E. (2012). La idea de la fenomenología. Herder Editorial.

Latorre, A., Del Rincón Igea, D., Arnal, J. (2020). Bases metodológicas de la investigación educativa. Ediciones Experiencia.

López-Arroyo, C. T. (2014). La enseñanza del patrimonio a partir del entorno próximo a los centros educativos. Propuesta didáctica. ÍBER. Didáctica de las Ciencias Sociales, Geografía e Historia, 78, 61-71.

López-Arroyo, C. T. (2017). Elpatrimonio en el contexto escolar. Análisis de concepciones como vehiculo para el desarrollo profesional docente. Experiencia didáctica: "Farmington Junior High y su entorno patrimonial". Utah. Tesis doctoral. Universidad de Huelva.

Lucas, L. y Delgado-Algarra, E. (2020). El Profesor Posmoderno de Ciencias Sociales: Un Modelo de Buenas Prácticas en Educación Patrimonial. REICE. Revista Iberoamericana sobre Calidad, Eficacia y Cambio en Educación, 18(1), 27-45.

Lucas L. y Estepa, J (2016). El patrimonio como instrumento para la formación de la ciudadanía crítica y participativa. Investigación en la escuela, 89, 35-48.

Luna, U., Ibáñez, A., Rivero P. (2019). El patrimonio aumentado. 8 apps de Realidad Aumentada para la enseñanza-aprendizaje del patrimonio. Revista interuniversitaria de formación del profesorado, 94, 43-62.

Marcus, G. y Fischer, M. (2004). La antropología como crítica cultural: un momento experimental en las ciencias bumanas. Amorrortu editores.

Martín, M. y Cuenca, J. M. (2015). Educomunicación del patrimonio. Educatio Siglo XXI, 33(1), 33-54.

Munilla, C. y Marín, S. (2020) Patrimonio y emociones. Estado de la cuestión desde la perspectiva internacional y nacional. Revista Interuniversitaria de Formación del Profesorado, 95(34.1), 177-196.

Prats, J. y Santacana, J. (2009). Ciudad, educación y valores patrimoniales. La ciudad educadora, un espacio para aprender a ser ciudadanos. Íber: Didáctica de las Ciencias Sociales, Geografía e Historia, 59, 8-21.

Pozuelos, F. J. (2007). Trabajos por proyectos en el aula: descripción, investigación y experiencias. Colección Colaboración Pedagógica, 18.

Rivero, T., López-Álvarez, M. y López-Facal, R. (2017). La compresión del paisaje partiendo de las emociones. En R. Martínez, R. García-Morís y C. R. García, Investigación en didáctica de las Ciencias Sociales. Retos, preguntas y líneas de investigación (pp. 751-761). Universidad de Córdoba.

Santacana, J. y Martínez, T. (2018). El patrimonio cultural y el sistema emocional: un estado de la cuestión desde la didáctica. Arbor, 194(788), 446. 
Stake, R. E. (2007). Investigación con estudio de casos. Ediciones Morata.

Trabajo, M y Cuenca J. M (2017) La educación patrimonial para la adquisición de competencias emocionales y territoriales del alumnado de enseñanza secundaria. Pulso: revista de educación, 40, 159-174.

Trabajo, M. y López-Cruz I. (2019). Implementación del programa Vivir y Sentir el Patrimonio en un centro de educación secundaria. Un mar de patrimonio. Ensayos: Revista de la Facultad de Educación de Albacete, 34(1), 55-66.

Vicent, N., Rivero, M. P. y Feliu, M. (2015). Arqueología y tecnologías digitales en Educación Patrimonial. Educatio siglo XXI: Revista de la Facultad de Educación, 33(1), 83-102.

Weber, M. (1982). Ensayos sobre metodología sociológica. Amorrortu editores.

Weber, M. (1984). La acción social: Ensayos metodológicos. Península.

Zuber-Skerritt, O. (1996). New directions in action research. Routledge. 